\title{
Going Up!
}

Ken Davidian

\section{Associate Editor}

$\mathrm{B}$

eginning with Russia and the United States in the 1950s, space industry corporations from many other countries began designing and building liquid rocket engines (LREs) in the following decades. As new countries joined the LRE business, they each used increasingly modern technologies and achieved higher levels of manufacturing efficiencies. Most recently, SpaceX in the United States has established their LRE manufacturing capability, using more advanced manufacturing techniques and materials than their predecessors.

Despite this constant improvement in LRE manufacturing capability, the physics of rocketry hasn't changed. The chances are against a substantial increase in LRE performance over what has been accomplished to date. If the performance of LREs cannot be improved beyond current limits, how will it be possible to substantially reduce the cost of getting into Earth orbit or escaping Earth's gravity well altogether? There are many alternative transportation methods that have been researched or are currently being developed, but one particular solution that has received special attention recently in the United States is the space elevator. Specifically, the space elevator was the namesake of a prize offered by the National Aeronautics and Space Administration (NASA) under the Centennial Challenges program. ${ }^{1}$ The competition was based on the development of two key technologies: power beaming and high-strength material. Realization of the space elevator concept relies on substantial developments in both these technologies. The power beaming competition was conducted more than 5 years ago, and a $\$ 900,000$ purse was won in 2009 by Team LaserMotive. ${ }^{2}$ The high-strength material prize was never won. ${ }^{3}$
The space elevator concept was originally proposed by Konstantin Tsiolkovsky in 1895 and has been cited in popular science-fiction literature by Clarke (The Fountains of Paradise), Heinlein (Friday), and Robinson (Red Mars), among others.

In October 2014, Scott Hubbard and I asked Dr. Peter Swan if he would like to be a guest editor for a special edition of the New Space journal. Dr. Swan specializes in space elevators and had completed a study on the topic for the International Academy of Astronautics in 2013. We asked if he could assemble a suite of articles for the New Space journal that could tell a comprehensive story about space elevators to our readers. The products of his efforts and of the authors with whom he works are presented in this issue. The issue contains a historic overview of space elevators, encompassing the past, present, and future of this promising transportation technology. Two reports present the technological perspectives of the space elevator and its supporting infrastructure. All the authors of the reports in this issue are members of the International Space Elevator Consortium (ISEC), a nonprofit organization that was established to provide technical support, public awareness, and STEM education services in the promotion, development, construction, and operation of space elevator infrastructures.

\section{REFERENCES}

1. Wilson J. 2015. Centennial challenges. Retrieved October 12, 2015, from www.nasa.gov/directorates/spacetech/centennial_challenges/index.html

2. Dunbar B. 2009. LaserMotive wins $\$ 900,000$ from NASA in space elevator games. Retrieved October 12, 2015, from www.nasa.gov/centers/dryden/status_reports/ power_beam.html\#.VhuZuXqqqko

3. Dunbar B. 2011. NASA-Strong tether challenge. Retrieved October 12, 2015, from www.nasa.gov/offices/oct/early_stage_innovation/centennial_challenges/ tetherl 